
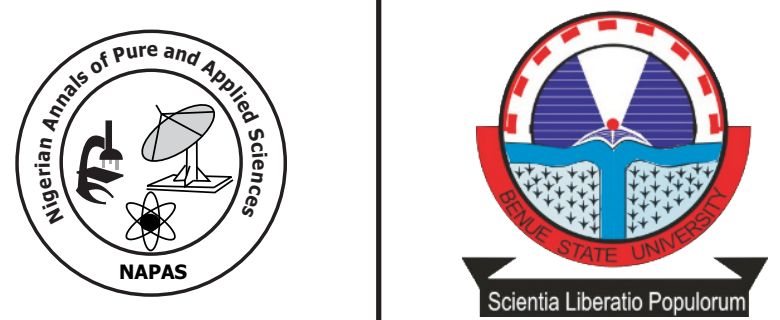

\title{
Optimal Selection of Portfolio in Nigerian Stock Exchange using Dynamic Programming
}

\author{
Umar Muhammad Modibbo \\ Department of Statistics and Operations Research \\ Modibbo Adama University of Technology, Yola-Nigeria \\ Email:umarmodibbo@mautech.edu.ng.
}

\begin{abstract}
Investment in various types of assets is an exciting choice of most successful business entrepreneurs. Investors have no option than to make a holistic decision regarding the position of their wealth within the context of the portfolio. In this paper, a Dynamic Programming (DP) algorithm and Modern Portfolio Theory (MPT) were used to determine the optimal returns of investments and the risks involved. Also, the correlation between expected returns and risk of investments were analyzed. Data of four securities were collected from the Nigeria Stock Exchange, Yola, for the sample period of 2016. Dynamic programming was found to be a more efficient algorithm for determining how much to invest in each investment portfolio. Through the analysis of the investments, OANDO PLC and Nigeria Breweries were respectively selected with high optimal returns of N426000. That is, investing N5 million in OANDO PLC yields a return of N269000 and N4 million in Nigeria Breweries yields N160000. One observation about these investments is that they all have a high risk of investment.
\end{abstract}

Key words: Dynamic Programming, Nigerian Stock Exchange, Portfolio Selection, Investment Returns. 


\section{Introduction}

Efficient allocation of funds is an essential critical functionality of any financial institution in modern times. Investors need to have a guided decision as regards to the company they may wish to invest in, and the degree of investment (Brown et al., 1990). However, selecting investments based on the allocation of fund and future returns alone is not sufficient. Many players invest their resources in more than one company suggests that there are other factors besides allocation of fund and returns which need to be considered. The investors not only like returns but also dislike risk. Several surveys of investor's behavior showed that organization, individual preferences are also being affected by risk. (Nagy \& Obenberger, 1994, Beal et al., 2005). Risk can be defined differently by different individual investors; what is the risk for one investor may not be a risk for the other. However, there may be an ordinary risk for all investors. For example, market fluctuation may result in the loss of a certain proportion of investment which is a common risk to all investors. At the same time, improper decision making or inadequate income to invest might be a particular risk to the investor's concern. Generally, risk can be viewed as the probability of not achieving an objective(s) of the decisionmaker; hence it is part and parcel of the investment. Importantly, a good investor is one who can be able to quantify and manage these risks within the horizon of portfolio investment. Taking high-risk yield for higher returns, if an investor takes a greater risk in short-term bases, he may undoubtedly receive higher returns in the long-term run, which will make his ultimate investment objectives being achieved. Too much of the risk may jeopardize the business and too little may hinder the attainments of the ultimate goal.

Injecting money in various types of assets is an exciting choice of most successful business entrepreneurial; investors employ funds or buy shares in different outlet with the sole aim of earning rewards in terms of income, capital or goodwill appreciation (Pandian, 2015). Investment is the sacrifice or sinking of capital or money into a business by way of purchasing shares, assets or any financial instrument with the hope of gaining a profit in returns which may be in terms of interest, income, goodwill or instrumental value appreciation (Gupta and Hira, 2002).

\section{The Nigerian Stock Exchange (NSE)}

Stock exchange is a place where buyers or sellers of shares, stocks, government bonds, debentures and other securities can do market through the members of the stock brokers (Anyanwu, 1993). The NSE bearing Lagos Stock Exchange was on the March $1^{\text {st }}, 1959$ registered and issued business certificate, it was incorporated on September $5^{\text {th }}, 1960$ and began operations on the $5^{\text {th }}$ June, 1961 (Nwankwo, 1988; Okonkwo et al., 2019). It was later transformed to NSE on the $2^{\text {nd }}$ December, 1977 (Adanma et al., 2015). The NSE activities are regulated by the Nigerian Securities and Exchange Commission (SEC). Some of the functions of NSE are promoting further offerings of stock and shares to the general public; participation of private sector into the economy and providing opportunity for foreign capital attraction to the national development. It has a responsibility of facilitating the purchasing and selling of securities in order to reduce the risk of liquidity, foreign investments in Nigerian manufacturing sector to enhance government joint ventures with foreign nations, and serve as a meeting point for members to buy and sell existing stocks and shares as well as granting quotations to new members. Since inception of NSE, many more branches were opened in Kaduna, Kano, Port Harcourt, Onitsha, Yola and Abuja with its headquarters in Lagos. It has over 169 listed securities as at May $1^{\text {st }}, 2018$ according to (Okonkwo et al., 2019).

\section{Literature Review}

Research in the field of optimal portfolio selection has a long tradition and has been conducted by different scholars using a variety of techniques and methodologies. Recently, Stocks in the Nigerian Capital Market was analyzed using wavelet by (Okonkwo et al., 2019). A common technique used in studying this phenomenon is dynamic programming (DP). For instance, Yan and Bai (2009) studied financial and real investment by formulating a DP model in other to allocate resources between different stocks in a portfolio to realize maximum profit. Optimal asset allocation was considered in a multi-period investment by (Pola, 2006). A stochastic DP was used to 
address multi-period investment portfolio by (Herman, 2009), Rockafellar and Uryasev, (2000) solved Portfolio optimization problems with DP and Monte Carlo simulations to capture the risk in each associated investment. Ant Colony Optimization (ACO) algorithm was used to optimally predict the next day closing stock price by (Ahmed et al., 2019). Many kinds of research on portfolio selection and investment risk quantification using mathematical programming can be found in (Wilkens and Zhu, 2001); (Vercher et al., 2007); (Wang and Zhu, 2002); (Amiri and Heidary, 2018), (Xidonas et al., 2018); (Zhang, 2019); (Mishra and Ram, 2020); (Galankashi et al., 2020) amongst others.

\section{Materials and Methods}

In this section, two approaches were used to analyze the portfolio selection problem. These are the Dynamic Programming (DP) and Modern Portfolio Theory (MPT).

\section{Dynamic Programming Technique}

Dynamic Programming (DP) is an operational research technique useful for making sequential interrelated decisions. It provides a procedure for determining an optimal combination of decisions systematically.

\section{Features of dynamic programming}

The basic features which characterize dynamic programming problems are presented and briefly discussed here.

a. The problem can be partition into stages, with a required policy decision at each stage.

b. A number of states exist at each stage associated with its beginning.

c. Each stage, transform the current state to a state associated with the beginning of the next stage according to a probability distribution.

d. Design the solution procedure to find the optimal policy for the overall problem.

e. Given the current state, an optimal policy for the remaining stages is independent of the adopted policy in the previous stages.

f. The procedure begins by finding the optimal policy for the last stage.

A recursive relation is available which identifies the optimal solution for stage $n$, given the optimal policy for stage $n+1$

\section{Dynamic Programming Model Formulation}

Let stage be the number of securities to be considered and hence the problem is divided into $F$, for $\mathrm{i}=1,2, \ldots, 4$

Let the state be the amount of money available for investment denoted by decision variables $x$, and the optimal decision at stage $i$ is denoted by $d i$

$F_{i}(X)=$ The optimum profit/return obtained by an optimal set of decisions at stage $n$ and for state $x$

$Z=$ The unit considered for investment from the total amount $x$.

$\mathrm{g}_{i}(X)=$ The return for investment $i$, when $z$ unit are invested

Therefore, the recursive model of the DP problem can be formulated as:

$F_{n}(x)=\operatorname{Max}\left[g_{\mathrm{i}}(z)+f_{i+1}(x-z)\right]$

\section{Modern Portfolio Theory (MPT)}

This approach is also known as MeanVariance Analysis. It is a mathematical framework that is used to assemble portfolio assets in a manner that optimizes the expected return for a given level of variance defines as a risk. According to this concept, returns and risk of the asset cannot be assessed by itself; rather, how it contributes to the overall risk and returns of the portfolio (Markowitz, 1991). Markowitz developed a model based on the expected rate of return and expected risk of the portfolio and concluded that the variance of the rate of return is a sensible measure of risk. Returns can be maximized by minimizing the total risk of a portfolio through diversification.

\section{MPT Model Formulation}

Let $R i$ denotes the observed return of assets for $\mathrm{i}=1 \ldots \mathrm{N}$, and $m$ represent the number of return of the portfolio. Also, let the amount invested and the one received be denoted by $W_{o}$ and $W_{1}$ respectively, and the risk of the portfolio defined by $y$. Therefore, for $i=1$, the return of assets observed would be

$R_{1}=\frac{W_{1}}{W_{0}}$ 
Similarly, the remaining returns of assets can be calculated. Let the average return for assets $i$ be calculated as

$\mu=\sum_{i=1}^{n} \frac{R_{i}}{N}$

And the variance and standard deviations for the respective returns be given by eqn. 4 and 5 accordingly.

$\sigma^{2}=\sum_{i=1}^{n} \frac{\left(R_{i}-\mu\right)^{2}}{N-1}$

$\sigma=\sqrt{\sigma^{2}}$

Whereas, the mean of the portfolio returns and that of its risk are given by eqn. 6 and 7 respectively.

$\bar{m}=\sum_{i=1}^{n} \frac{m_{i}}{N}$
$\bar{Y}=\frac{\sum_{i=1}^{N} Y_{i}}{N}$

The covariance and the correlation coefficient between $m$ and $y$ are stated in eqn. 8 and 9 below

$$
\begin{aligned}
\sigma_{m y} & =\sum \frac{(\boldsymbol{m}-\overline{\boldsymbol{m}})(\boldsymbol{Y}-\overline{\boldsymbol{Y}})}{N-1} \\
\rho_{m y} & =\frac{\sigma_{m y}}{\sigma_{m \sigma_{y}}}
\end{aligned}
$$

\section{Data Presentation}

This section presents the data use in the analysis of this research. We considered four securities from the Nigeria Stock Exchange, Yola, for the sample period of 2016. These data include OANDO PLC Nigeria, Zenith Bank, Stanbic IBTC Holding PLC, and Nigeria Breweries. The amount of money in millions, invested in the four securities and the returns in thousand are shown in Table 1.

Table 1: Investments and Returns of Four Securities

\begin{tabular}{lllllllllll}
\hline $\begin{array}{l}\text { Securities } \\
\mathrm{g}_{\mathrm{i}}(\mathrm{x})\end{array}$ & 0 & 1 & 2 & 3 & 4 & 5 & 6 & 7 & 8 & 9 \\
\hline $\mathrm{g}_{1}(\mathrm{x})$ & 0 & 21 & 108 & 161 & 215 & 269 & 109 & 144 & 141 & 159 \\
$\mathrm{~g}_{2}(\mathrm{x})$ & 0 & 32 & 2 & 4 & 5 & 6 & 11 & 11 & 22 & 22 \\
$\mathrm{~g}_{3}(\mathrm{x})$ & 0 & 18 & 80 & 120 & 160 & 200 & 73 & 85 & 97 & 109 \\
$\mathrm{~g}_{4}(\mathrm{x})$ & 0 & 4 & 2 & 3 & 4 & 5 & 60 & 70 & 80 & 90 \\
\hline
\end{tabular}

Source: (Nigerian Stock Exchange Yola)

Key: Oando Plc $=g_{1}(x)$, Zenith Bank $=g_{2}(x)$, Nigeria Berweries $=g_{3}(x)$, Stanbic Ibtc Holding Plc $=g_{4}(x)$

\section{Result analysis and discussion}

Based on the data in Table 1, MPT and DP models were formulated and used to find the risk and corresponding returns involved in various investments. The return from each security is computed in light of equation 1 and presented in Table 2.

Table 2: Returns from the various Investments

\begin{tabular}{ccccc}
\hline $\mathrm{X}$ & $\mathrm{F} 1$ & $\mathrm{~F} 2$ & $\mathrm{~F} 3$ & $\mathrm{~F} 4$ \\
\hline 0 & 0 & 0 & 0 & 0 \\
1 & 32 & 32 & 18 & 4 \\
2 & 108 & 80 & 80 & 4 \\
3 & 161 & 120 & 120 & 3 \\
4 & 215 & 160 & 160 & 4 \\
5 & 269 & 200 & 200 & 5 \\
6 & 301 & 232 & 204 & 60 \\
7 & 349 & 236 & 202 & 70 \\
8 & 389 & 234 & 203 & 80 \\
9 & 429 & 235 & 204 & 90 \\
\hline
\end{tabular}


The total expected return will be: $\mathrm{F}_{1}(5)+$ $\mathrm{F}_{2}(0)+\mathrm{F}_{3}(4)+\mathrm{F}_{4}(0)=269+0+160+0=429$. Table 3 shows that with N9 million available for investment. It becomes unattractive to invest in Zenith Bank and Stanbic IBTC Holding PLC.
One should, however, invest N5 million in OANDO PLC to get N269000 and N4 million in Nigeria Breweries to get N160,000 which yield a maximum return of N429,000. The optimal investment is presented in Table 3 .

Table 3: Optimal Returns for the Investment

\begin{tabular}{lcccc}
\hline Investment $\mathrm{g}_{\mathrm{i}}(\mathrm{x})$ & 1 & 2 & 3 & 4 \\
\hline Amount invested & 5 & 0 & 4 & 0 \\
Optimal returns & 269 & 0 & 160 & 0 \\
\hline
\end{tabular}

The MPT approach is used to compute the various means, variances (risks) and standard deviations for the investment portfolios as well as the correlations between the optimal investment returns and risks and the results are shown in Table 4 and 5 respectively.

Table 4: Average investment portfolio return, variance and standard deviation

\begin{tabular}{lccc}
\hline Investment $(\boldsymbol{\mu})$ & Mean $\left(\boldsymbol{\sigma}^{2}\right)$ & Variance $(\boldsymbol{\sigma})$ & Standard deviation \\
\hline $\mathrm{g}_{1}(\mathrm{x})$ & 31.2 & 399.1 & 19.98 \\
$\mathrm{~g}_{2}(\mathrm{x})$ & 4.5 & 93.7 & 9.68 \\
$\mathrm{~g}_{3}(\mathrm{x})$ & 22.6 & 229.1 & 15.14 \\
$\mathrm{~g}_{4}(\mathrm{x})$ & 4.8 & 21.1 & 4.59 \\
\hline
\end{tabular}

Table 5: Correlations between Investment Return and Risk

\begin{tabular}{llll}
\hline Investment & Returns & Risk & Correlation Coefficient \\
$\mathrm{g}_{1}(\mathrm{x})$ & 269 & 399.1 & \\
$\mathrm{~g}_{2}(\mathrm{x})$ & 0 & 93.7 & 0.9796 \\
$\mathrm{~g}_{3}(\mathrm{x})$ & 160 & 229.1 & \\
$\mathrm{~g}_{4}(\mathrm{x})$ & 0 & 21.1 & \\
\hline
\end{tabular}

From Table 5, it can be seen that the correlation between expected returns and risk of investment is 0.9796 . The analysis shows that there is a strong positive correlation between expected returns and the risk of investment. High expected returns could be attributed to the high risk of investment, which means that a short term investment should be adopted in any of the investments. That is a portfolio with long term investment is strictly not advisable.

\section{Managerial Insights and Practical Implications}

This research will help managers in the stock exchange to realize the potential of data analysis and to adjust to more profitable ventures to capture the will of investors. Since Zenith Bank and Stanbic IBTC Holdings PLC were not profitable based on the available data and analysis, it can be seen that their total contribution to the portfolio return were zeros.
No investor will be interested in investing in these companies. One sharp observation about these investments is that they all have a high risk of investment. Also, the returns from these investments are very high. There is a strong positive correlation between expected returns and risk of the investments.

\section{Research Findings}

This research work contributes to the body of literature in investment and portfolio management. From the DP, MPT algorithms and correlation coefficient analysis, it was found that the optimal investment return was $\mathrm{N}$ 429,000. OANDO PLC and Nigeria Breweries were the prime investments which contributed most to the optimal expected return. The problem could be solved in any direction without any particular arrangement of the investment-however, the optimal solution obtained by a backward recursion. The DP 
provided the optimal policy for the portfolio problem by evaluating the whole of possibilities and making at each point in time, the decision that would imply higher future expected revenues and processing backward recursion.

\section{Conclusion and Future Research}

Selecting securities and their Continuous shifting horizon of the portfolio to maximize returns that best satisfy the objectives of an investor requires optimization knowledge and the financial expertise in choosing the optimal mix of the securities. We have used the DP algorithm to analyze four securities, and a maximum return of N429000 obtained from an investment of $\mathrm{N} 9$ million. This optimal return did not include the contributions from the Government of Zenith Bank and Stanbic IBTC Holding PLC, because the DP algorithm rejected these investments. Any attempt to invest in these investments will seriously affect returns, and as such, no investor would be ready to risk his hard-won resources. The MPT is employed to measure the risk of this investment, as shown in Table 4 and 5. Usually, an investor will invest where there are minimum risk and very high returns. In this case, the investor is interested in investing in a portfolio where there is a higher risk with the highest returns. It has confirmed the fact that all investors are riskaverse, That is, they will only accept the more significant risk if compensated with the higher expected return. The study revealed that there is a strong positive correlation between expected returns and risk of the investments. The higher the risk, the better the expected returns. The study recommends DP and MPT in solving investors' problems of where and how much to invest in their allocations of funds for optimum returns with minimal risk. The major limitation of the research is that only four securities are used and the maximum amount of nine million naira to be invested. In future, more securities could be considered, and the study is extended to cover Nigeria at large.

\section{Acknowledgement}

I wish to acknowledge the editor of NAPAS, the anonymous reviewers for their valuable suggestion which improved the quality and presentation of the paper and the Nigerian Stock Exchange Yola Branch for making the data available for this research.

\section{References}

Ahmed, M. K., Wajiga, G. M., Blamah, N. V., \& Modi, B. (2019). Stock Market Forecasting Using ant Colony Optimization Based Algorithm. American Journal of Mathematical and Computer Modelling, 4(3), 52-57.

Adanma, E. S., Oleka, D. C., and Nwanne, T. F. I. (2015). The Nigerian Stock Exchange: A Bane for Sustainable Economic Development. European Journal of Business and Social Sciences, 3(12), 17 27.

Amiri, M., \& Heidary, M. S. (2018). Portfolio optimization with obust possibilistic programming. Iranian Journal of Finance, 2(4).

Anyanwu, T. C. (1993) Monetary Economics Theory; Policy and Institutions Onitsha - Nigeria Hybrid Publishes Ltd, pp. 93

Beal, DJ, Goyen, M, and Phillips P. (2005). Why do we invest ethically? The journal of investing 14, 66-78.

Brown, D. B, Bulfin, and Deason,W. (1990)." Allocating highway safety funds." Transportation Research Record 1270, Transportation Research Board, Washington.

Galankashi, M. R., Rafiei, F. M., \& Ghezelbash, M. (2020). Portfolio selection: a fuzzyANP approach. Financial Innovation, 6(1), 1-34.

Gupta, P.K., \& Hira D.S. (2012). "Problems in operations research principles and solutions" S. Chand and company Ltd 2012 edition pg 583-603 \& 755

Markowitz, H. M. (1991). Foundations of portfolio theory. The journal of finance, 46(2), 469-477.

Mishra, R., \& Ram, B. (2020). Portfolio Selection Using R. Yugoslav Journal of Operations Research. DOI: https://doi. org/10.2298/YJOR181115002M.

Nagy, R. A., \& Obenberger, R. W. (1994). Factors influencing individual investor behavior. Financial Analysts Journal, 50(4), 63-68.Herman E.J (2009). Value of risk, the benchmark for controlling market risk Mcgraw-Hill, Chicago future. Financial practice and education 5(1): 7-15Okonkwo, C. U., Osu, B. O., Uchendu, K., \& Chibuisi, C. (2019). Wavelet Analysis of Stocks in the 
Nigerian Capital Market. NIGERIAN ANNALS OF PURE AND APPLIED SCIENCES, 1,176-183.

Pandian, R. (2015). A Study On Financial Derivatives (Futures \& Options). International Journal of Research in Business Management, 3(3), 1-15.

Pola, G., \& Pola, G. (2006, December). Optimal dynamic asset allocation: A stochastic invariance approach. In Proceedings of the 45th IEEE Conference on Decision and Control (pp.2589-2594). IEEE.

Rockafellar, R. T., \& Uryasev, S. (2000). Optimization of conditional value-atrisk. Journal of risk, 2, 21-42.

Vercher, E., Bermúdez, J. D., \& Segura, J. V. (2007). Fuzzy portfolio optimization under downside risk measures. Fuzzy sets and systems, 158(7), 769-782.

Wang, S., \& Zhu, S. (2002). On fuzzy portfolio selection problems. Fuzzy Optimization and Decision Making, 1(4), 361-377.
Wilkens, K., \& Zhu, J. (2001). Portfolio evaluation and benchmark selection: $\mathrm{A}$ mathematical programming approach. The Journal of Alternative Investments, 4(1), 9-19.

Xidonas, P., Hassapis, C., Mavrotas, G., Staikouras, C., \& Zopounidis, C. (2018). Multiobjective portfolio optimization: bridging mathematical theory with asset management practice. Annals of Operations Research, 267(12), 585-606.

Yan, F., \& Bai, F. (2009). Application of dynamic programming model in stock portfolio-under the background of the subprime mortgage crisis. International Journal of Business and management, 9(3), 178-182.

Zhang, P. (2019). Multi-period mean absolute deviation uncertain portfolio selection with real constraints. Soft Computing, 23(13), 5081-5098. 